\title{
Effects of Thujaplicins on the Promoter Activities of the Human SIRT1 and Telomere Maintenance Factor Encoding Genes
}

Fumiaki Uchiumi ${ }^{1,2}$, Haruki Tachibana ${ }^{3}$, Hideaki Abe ${ }^{4}$, Atsushi Yoshimori $^{5}$, Takanori Kamiya ${ }^{4}$, Makoto Fujikawa ${ }^{3}$, Steven Larsen $^{2}$, Asuka Honma $^{4}$, Shigeo Ebizuka ${ }^{4}$ and Sei-ichi Tanuma ${ }^{2,3,6,7 *}$

${ }^{1}$ Department of Gene Regulation, Faculty of Pharmaceutical Sciences, Tokyo University of Science, Noda-shi, Chiba-ken 278-8510, Japan

${ }^{2}$ Research Center for RNA Science, RIST, Tokyo University of Science, Noda-shi, Chiba-ken, Japan

${ }^{3}$ Department of Biochemistry, Faculty of Pharmaceutical Sciences, Tokyo University of Science, Noda-shi, Chiba-ken 278-8510, Japan

${ }^{4}$ Hinoki Shinyaku Co., Ltd, 9-6 Nibancho, Chiyoda-ku, Tokyo 102-0084, Japan

Institute for Theoretical Medicine, Inc., 4259-3 Nagatsuda-cho, Midori-ku, Yokohama 226-8510, Japan

${ }^{6}$ Genome and Drug Research Center, Tokyo University of Science, Noda-shi, Chiba-ken 278-8510, Japan

${ }^{7}$ Drug Creation Frontier Research Center, RIST, Tokyo University of Science, Noda-shi, Chiba-ken 278-8510, Japan

\begin{abstract}
Resveratrol (Rsv) has been shown to extend the lifespan of diverse range of species to activate sirtuin (SIRT) family proteins, which belong to the class III NAD+ dependent histone de-acetylases (HDACs).The protein deacetylating enzyme SIRT1 has been implicated in the regulation of cellular senescence and aging processes in mammalian cells. However, higher concentrations of this natural compound cause cell death. Therefore, novel compounds that have reduced cellular toxicity will be required for anti-aging therapy, especially for dermatological treatments. In this study, the Luciferase (Luc) expression vector pGL4-SIRT1 containing 396-bp of the 5'-upstream region of the human SIRT1 gene was transfected into HeLa S3 cells and Luc assay was performed. The results showed that treatments with the natural compound, $\alpha-, \beta$ - and $y$-thujaplicins increase the SIRT1 promoter activity more than that with Rsv. Moreover, we carried out multiple transfection of Luc reporter vectors containing 5'-upstream regions of various human telomere maintenance factor encoding genes, and observed that $\beta$-thujaplicin (hinokitiol) activates TERT, RTEL, TRF1, DKC1, RAP1 (TERF2IP) and TPP1(ACD) promoters. These results suggest that that the $\beta$-thujaplicin could be used as anti-aging drugs to delay cellular senescence through activating SIRT1 transcription along with strengthening stability of telomeres.
\end{abstract}

Keywords: Aging; Cellular senescence; Resveratrol; Shelterins; SIRT1; Telomere; Telomerase; Thujaplicin

\section{Introduction}

A natural polyphenolic compound Resveratrol (Rsv), which is known as a stimulator of $\mathrm{NAD}^{+}$-dependent deacetylases sirtuin (SIRT) family proteins, sirtuin, elongates lifespan of model animals [1-5]. Previously, we reported that Rsv moderately activates the human SIRT1 and TERT promoters inducing telomerase activity in HeLa-S3 cells [6,7]. Moreover, multiple transfection assays showed that promoter activities of the genes encoding human telomere maintenance factors (shelterin proteins) [8] are up-regulated by Rsv treatment [9], suggesting that natural polyphenol compounds, such as Rsv may affect chromosomal stabilities. Thus, Rsv and its related polyphenols are expected to become candidate drugs for anti-aging therapeutics. However, it should be noted that Rsv has cytotoxic effects by inducing apoptotic cell death, especially when it is used at higher doses [10-12]. Thus, in order to develop safe drugs with anti-aging effects, searching for alternative natural compounds that up-regulate SIRT1 and shelterin gene expression and elucidation of their induction mechanisms are required.

$\beta$-Thujaplicin, which is also known as hinokitiol, is a tropolone derivative found in the heartwood of cupressaceous plants [13]. It has been reported to have a variety of biological effects, including induction of apoptosis [14] and differentiation [15], and anti-inflammatory [16], anti-bacterial [17] and anti-fungal [18] effects. In this study, we examined the effects of thujaplicins on the promoter activities of the human SIRT1 and shelterin-encoding genes by multiple transient transfection and Luc reporter assay. Here, we show the up-regulating effects of three types of thujaplicins $(\alpha, \beta$ and $\gamma)$ on the promoter activities of the human SIRT1 and shelterin-encoding genes by multiple transient transfection and Luc reporter assay. Here, we show that $\beta$-thujaplicin (hinokitiol) is able to up-regulate these promoter activities. Furthermore, we propose that $\beta$-thujaplicin could be used as one of lead-compounds for developing anti-aging drugs.

\section{Materials and Methods}

\section{Materials}

trans-Resveratrol (Rsv) was purchased from Cayman Chem. (Ann Arbor, MI) [6,7]. $\alpha-, \beta$ - and $\gamma$-thujaplicins were purchased from Osaka Chemical Industry Ltd. (Osaka, Japan) [19]. Structures of these compounds are shown in (Figure 1).

\section{Cell culture}

Human cervical carcinoma (HeLa S3) cells [20] were grown in Dulbecco's modified Eagle's (DME) medium (WAKO Pure Chemical, Tokyo, Japan), supplemented with $10 \%$ fetal bovine serum (FBS)

*Corresponding author: Sei-ichi Tanuma, Department of Biochemistry, Faculty of Pharmaceutical Sciences, Tokyo University of Science, Tokyo University of Science 2641 Yamazaki, Noda-shi, Chiba-ken 278-8510, Japan, Tel:+81-4-7124-1501; Fax: +81-4-7121-3620; E-mail: tanuma@rs.noda.tus.ac.jp

Received June 30, 2012; Accepted July 06, 2012; Published July 12, 2012

Citation: Uchiumi F, Tachibana H, Abe H, Yoshimori A, Kamiya T, et al. (2012) Effects of Thujaplicins on the Promoter Activities of the Human SIRT1 and Telomere Maintenance Factor Encoding Genes. Pharmaceut Anal Acta 3:159. doi:10.4172/2153-2435.1000159

Copyright: (c) 2012 Uchiumi F. This is an open-access article distributed unde the terms of the Creative Commons Attribution License, which permits unrestricted use, distribution, and reproduction in any medium, provided the original author and source are credited. 


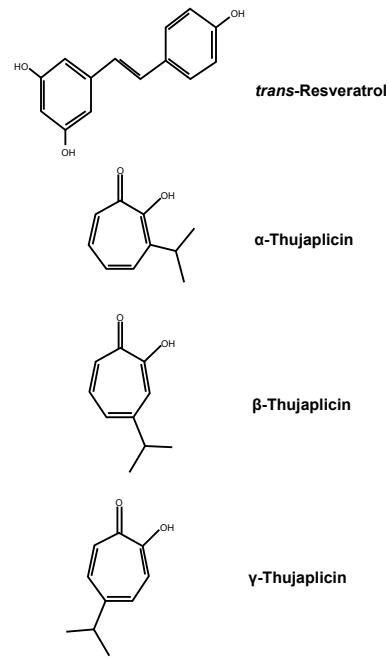

Figure 1: The structures of trans-Resveratrol and thujaplicins.

(Sanko Pure Chemical, Tokyo, Japan) and penicillin-streptomycin at $37^{\circ} \mathrm{C}$ in a humidified atmosphere with $5 \% \mathrm{CO}_{2}$.

\section{Construction of Luc reporter plasmids}

The Luc reporter plasmid pGL4-SIRT1 carrying 396-bp of the human SIRT1 promoter region was constructed as described previously [7]. Other Luc reporter plasmids, which contain 300 to 500-bp of 5'-upstream regions of the human PIF1, RTEL, TRF1, TRF2, TERT, TERC, TANK1, DKC1, TIN2, POT1, RAP1(TERF2IP) and TPP1(ACD) genes, were constructed as described previously $[9,21]$.

\section{Transient transfection and Luc assay}

Plasmid DNAs were transfected into HeLa S3 cells by the DEAEdextran method [20-22]. The DNA transfected cells were divided into at least four dishes. After $24 \mathrm{~h}$ of transfection, Rsv or thujaplicins were added to the culture medium. After a further $24 \mathrm{~h}$ of incubation, cells were collected and lysed with $100 \mu \mathrm{L}$ of $1 \mathrm{X}$ cell culture lysis reagent, containing $25 \mathrm{mM}$ Tris-phospate (pH 7.8), 2 mM DTT, $2 \mathrm{mM}$ 1,2-diaminocyclohexane-N,N,N',N',-tetraacetic acid, $10 \%$ glycerol and $1 \%$ Triton X-100, then mixed and centrifuged at $12,000 \times \mathrm{g}$ for $5 \mathrm{sec}$. The supernatant was stored at $-80^{\circ} \mathrm{C}$. The Luc assay was performed with a Luciferase assay system (Promega) and relative Luc activities were calculated as described previously [20-22]. Multiple transfection of human shelterin promoter-containing Luc reporter plasmids with 96-well culture plate was performed as described previously $[8,21]$.

\section{Results}

\section{Effects of thujaplicins on the human SIRT1 promoter}

To examine whether the human SIRT1 promoter is affected by $\alpha-, \beta-$ and $\gamma$-thujaplicins [19], transient transfection and Luc assays were carried out. Luc activities of pGL4-SIRT1 transfected cells were normalized to that of non-treated control cells. As shown in Figure $2 \mathrm{~A}$, the relative Luc activity of pGL4-SIRT1-transfected cells was prominently augmented by the addition of Rsv $(10 \mu \mathrm{M})$ or $\alpha-, \beta-$ and $\gamma$-thujaplicins $(10 \mu \mathrm{M})$ to the culture medium.

To examine the dose-dependent response to $\beta$-thujaplicin (hinokitiol), HeLa S3 cells were treated with 0 to $100 \mu \mathrm{M}$ of $\beta$-thujaplicin after $24 \mathrm{~h}$ of transfection and collected after further 24 $\mathrm{h}$ incubation (Figure 2B). The half maximal effective concentration $\left(\mathrm{EC}_{50}\right)$ was estimated as $3.1 \mu \mathrm{M}$. These results indicate that $10 \mu \mathrm{M}$ of $\mu$-thujaplicin is enough to induce SIRT1 promoter activity equal to Rsv $(10 \mu \mathrm{M})$ treatment.

\section{Effect of $\boldsymbol{\beta}$-thujaplicin on the 5 '-upstream regions of human genes encoding telomere maintenance factors}

Multiple transcription experiments were carried out with various Luc reporter plasmids containing 5'-flanking regions of the human shelterin encoding genes (Figure 3) [9]. By performing the multiple Luc assay, the effect of $\beta$-thujaplicin on these transcription-regulatory regions were examined. The results showed that $\beta$-thujaplicin $(10 \mu \mathrm{M})$ could induce up-regulation of relative promoter activities of the RTEL, TRF1, TRF2, TERT, DKC1, TIN2, RAP1(TERF2IP) and TPP1(ACD) genes (Figure 3). Approximate 1.5 to 2 -folds increases as compared with non-treated cells were observed in a similar manner as the 396-bp of the SIRT1 promoter (Figure 2A).

\section{Discussion}

It has been suggested that both cellular senescence and aging of organisms are accelerated by various factors, such as telomereshortening [23-25] and DNA damaging reactive oxygen species (ROS) that are mainly generated from mitochondria [26,27]. On the other hand, an important fact for anti-aging is the demonstration that caloric restriction elongates lifespans of organisms [28], suggesting that metabolism regulatory systems could control lifespan. Genetic analyses of C.elegans showed that several genes encoding insulin/IGF1 receptor and transcription factor FoxO play important roles in controlling the lifespan [29]. Moreover, studies of budding yeast showed that Sir2, a member of the sirtuin proteins with an $\mathrm{NAD}^{+}$-dependent protein

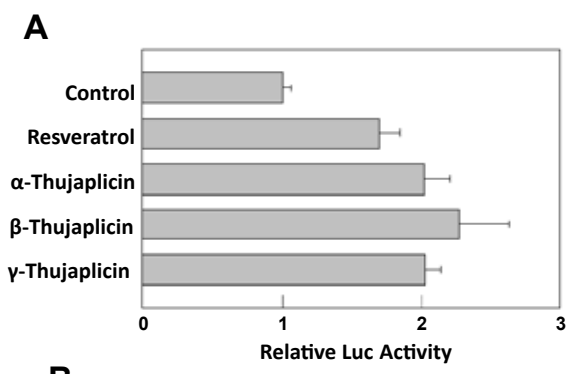

B

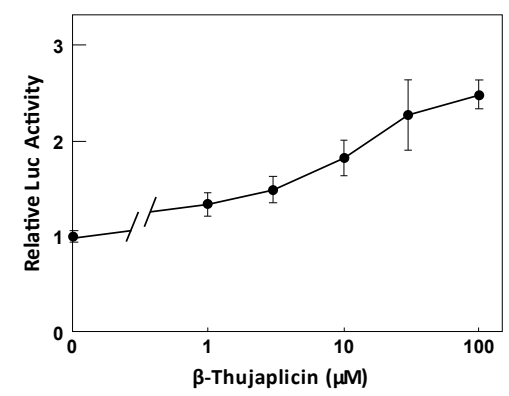

Figure 2: Effects of thujaplicins on the human SIRT1 promoter activity. (A) The Luc reporter plasmid, pGL4-SIRT1 [6,7], was transfected into HeLa S3 cells as described under Materials and Methods. After $24 \mathrm{~h}$ of transfection, cells were treated with Rsv $(10 \mu \mathrm{M})$, then harvested after a further $24 \mathrm{~h}$ incubation. (B) A similar (experiment was performed as in (A) with 0 to $100 \mu \mathrm{M}$ of $\beta$-thujaplicin The results show relative Luc activities of the indicated Luc reporter plasmidtransfected cells relative to those of non-treated cells. The values are the mean $\pm \mathrm{SD}$ of four independent assays. 


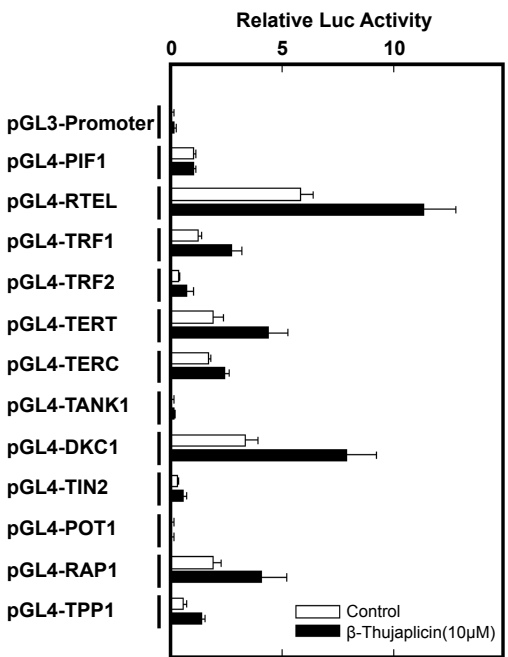

Figure 3: The effect of $\beta$-thujaplicin on the promoter activities of 5 '-upstream regions of human shelterin encoding genes. Reporter plasmids $(10 \mathrm{ng})$ and DEAE-dextran were spotted and dried onto each well of the 96-well culture plate. HeLa S3 cells $\left(1 \times 10^{5} /\right.$ well) were used for transfection and incubated for further $24 \mathrm{~h}$, then treated with $\beta$-thujaplicin $(10 \mu \mathrm{M})$ for $24 \mathrm{~h}$. Results show relative Luc activities from various Luc reporter transfected cells compared with that of pGL4-PIF1 transfected cells.

deacetylase activity, has silencing action on chronological aging of yeast cells [30]. Many proteins, including PGC-1a, p53, FOXO1, HIF1a, UCP2 and PPAR $\gamma$, have been reported to be the targets of SIRT1, which is known as mammalian homologue of Sir2 [31]. Because these protein factors function as metabolism regulators, SIRT1 could become a key regulator of healthspan of organisms [31].

In this study, we have examined promoter activities of the 396-bp 5 -flanking region of the human SIRT1 gene to find out its response to the treatments with three types of thujaplicins $(\alpha, \beta$ and $\gamma)$ in HeLa-S3 cells. The 396-bp region has no apparent TATA-box but contains several well known transcription factor binding elements, including CREB, C/EBP $\beta$, c-ETS, USF, SREBP1, Sp1, GATA and c-MYC binding motifs [7]. It has been shown that FOXO1, CREB, PPAR proteins and PARP2 play roles in regulation of the SIRT1 promoter [31]. However, at present, the Rsv or $\beta$-thujaplicin-responsive elements in the SIRT1 promoter region have not been precisely determined. Previously, it was indicated that the 5'-upstream regions of the WRN, BLM, TERT, p21 (CDKN1A) and HELB genes possess one or more Sp1/GC-box elements and that they positively respond to Rsv treatment in HeLa S3 cells $[6,32]$. The GC-box consensus sequence of the Sp1 transcription factor binding site is: 5'-(G/T)GGGCGG(G/A)(G/A)(C/T)-3' or 5'$(\mathrm{G} / \mathrm{T})(\mathrm{G} / \mathrm{A}) \mathrm{GGCG}(\mathrm{G} / \mathrm{T})(\mathrm{G} / \mathrm{A})(\mathrm{G} / \mathrm{A})(\mathrm{C} / \mathrm{T}) \mathrm{3}^{\prime}$ [33]. It has been shown that two GC-boxes, 5'-AGGGCGGGGG-3' and 5'GGGGCGGGTC -3' ( -83 to -74 and -66 to -57 , respectively), play important roles in the SIRT1 promoter activity [34]. As shown in Figure 3, the 5'-upstream regions of the RTEL, TRF1, TRF2, TERT, DKC1, TIN2, RAP1 and TPP1 genes positively responded to the treatment with $\beta$-thujaplicin. All of the 5'-upstream regions in the Luc-reporter vectors except pGL4-RTEL have at least one Sp1/GC-box. Although TF search analysis did not find Sp1/GC-box, 5'-CGGGCGGGAC-3', 5'-TTTCCGCCGG-3' and 5'-TGCGCGCCTC-3', namely GC-box like sequences are contained in the pGL4-RTEL. Taken together, the Sp1 binding motif is possibly one of the candidate elements that respond to $\beta$-thujaplicin. Moreover, Rsv is known to up-regulate cAMP level to activate CREB, which plays important roles in hormonal metabolism, including that of the insulin signaling system [35]. The CREB element is located in the 5'-upstream regions of the RTEL [21] and TPP1 [9] genes. This suggests that the CREB element in the human SIRT1 promoter region (-288 to -281) may respond to the $\beta$-thujaplicin treatment.

It should be noted that $\beta$-thujaplicin (hinokitiol) has been shown to stabilize transcriptional active HIF-1 $\alpha$ in HeLa and HepG2 cells to increase transcription of the VEGF gene [36]. On the other hand, SIRT1 deacetylates HIF-1 $\alpha$ to suppress its activity [37]. Therefore, the induction of SIRT1 gene expression by $\beta$-thujaplicin might function to reduce over-stimulated HIF- $1 \alpha$ for the maintenance of cellular homeostasis. Moreover, it has been reported that $\beta$-thujaplicin induces G1 arrest via down-regulation of phosphorylated Rb and Skp2 ubiquitin ligase [38]. This cell cycle arrest is accompanied with an increase of p27 and 21 protein levels. Although the precise molecular mechanisms are remain unclear, these biological properties of $\beta$-thujaplicin including transcriptional regulation and antiviral activity $[16,36]$ might originate from its specific structure (Figure 1) that can act as a chelator of divalent metal ions [39]. In this study, we observed the up-regulation of the SIRT1 and shelterin-encoding gene promoter activities by the treatment of $\beta$-thujaplicin. Moreover, the comparisons of 5 '-upstream regions of those genes suggested that transcription factors, including $\mathrm{Sp} 1$, may control lifespans of organisms responding to $\beta$-thujaplicin. The core structure of the thujaplicins could be applied to design lead compounds for novel anti-aging drugs, which could simultaneously activate the SIRT1 and shelterin-encoding gene promoter activities.

\section{Acknowledgments}

The authors are grateful to Tsutomu lijima and Masanao Taniura for their outstanding technical assistance. This work was supported in part by a Research Fellowship grant from the Research Center for RNA Science and Drug Creation Frontier Research Center, RIST, Tokyo University of Science.

\section{References}

1. Stefani M, Markus MA, Lin RC, Pinese M, Dawes IW, et al. (2007) The effect of resveratrol on a cell model of human aging. Ann NY Acad Sci 1114: 407-418.

2. Kaeberlein M (2010) Resveratrol and rapamycin: are they anti-aging drugs? Bioessays 32: 96-99.

3. Howitz KT, Bitterman KJ, Cohen HY, Lamming DW, Lavu S, et al. (2003) Small molecule activators of sirtuins extend Saccharomyces cerevisiae life span. Nature 425: 191-196.

4. Wood JG, Rogina B, Lavu S, Howitz K, Helfand SL, et al. (2004) Sirtuin activators mimic caloric restriction and delay ageing in metazoans. Nature 430 : 686-689.

5. Viswanathan M, Kim SK, Berdichevsky A, Guarente L (2005) A role for SIR-2.1 regulation of ER stress response genes in determining $C$. elegans life span. Dev Cell 9: 605-615.

6. Uchiumi F, Watanabe T, Hasegawa S, Hoshi T, Higami Y, et al. (2011) The effect of resveratrol on the Werner Syndrome RecQ helicase gene and telomerase activity. Curr Aging Sci 4: 1-7.

7. Uchiumi F, Tachibana H, Larsen S, Tanuma S (2012) Effect of lignin glycosides extracted from pine cones on the human SIRT1 promoter. Pharm Anal Acta S8: 001

8. Sfeir A, de Lange T (2012) Removal of shelterin reveals the telomere end protection problem. Science 336: 593-597.

9. Uchiumi F, Oyama T, Ozaki K, Tanuma S (2011) Chapter 29: Characterization of 5'-flanking regions of various human telomere maintenance factor-encoding genes. In: DNA Repair (Kruman I, Ed.), InTech-Open Access Publisher, Inc Rijeka, Croatia: 585-596.

10. Calabrese EJ, Mattson MP, Calabrase V (2010) Resveratrol commonly displays hormesis: Occurrence and biomedical significance. Hum Exp Toxicol 29: $980-1015$ 
Citation: Uchiumi F, Tachibana H, Abe H, Yoshimori A, Kamiya T, et al. (2012) Effects of Thujaplicins on the Promoter Activities of the Human SIRT1 and Telomere Maintenance Factor Encoding Genes. Pharmaceut Anal Acta 3:159. doi:10.4172/2153-2435.1000159

11. Gogada R, Prabhu V, Amadori M, Scott R, Hashmi S, et al. (2011) Resveratrol induces p53-independent, X-linked inhibitor of apoptosis protein (XIAP)mediated Bax protein oligomerization on mitochondria to initiate cytochrome $\mathrm{C}$ release and caspase activation. J Biol Chem 286: 28749-28760.

12. Lin HY, Tang HY, Davis FB, Davis PJ (2011) Resveratrol and apoptosis. Ann NY Acad Sci 1215: 79-88.

13. Nakano H, Ikenaga S, Aizu T, Kaneko T, Matsuzaki Y, et al. (2006) Human metallotionein gene expression is upregulated by $\beta$-thjaplicin: possible involvement of protein kinase $\mathrm{C}$ and reactive oxygen species. Biol Pharm Bul 29: 55-59.

14. Ido Y, Muto N, Inada A, Kohroki J, Mano M, et al. (1999) Induction of apoptosis by hinokitiol, a potent iron chelator, in teratocarcinoma F9 cells is mediated through the activation of caspase-3. Cell Prolif 32: 63-73.

15. Tanaka T, Satoh T, Onozawa Y, Kohroki J, Itoh N, et al. (1999) Apoptosis during iron chelator-induced differentiation in F9 embyonal carcinoma cells. Cell Biol Int 23: 541-550.

16. Byeon SE, Lee YG, Kim JC, Han JG, Lee HY, et al. (2008) Hinokitiol, a natura tropolone derivative, inhibits TNF- $\alpha$ production in LPS-activated macrophages via suppression of NF-kB. Planta Med 74: 828-833.

17. Manter KD, Kelsey RG, Karchesy JJ (2007) Antimicrobial activity of extractable conifer heartwood compounds toward Phytophthora ramorum. J Chem Ecol 33: 2133-2147

18. Komaki N, Watanabe T, Ogasawara A, Sato N, Mikami T, et al.(2008) Antifungal mechanism of hinokitiol against Candida albicans. Biol Pharm Bull 31: 735-737.

19. Takahashi S, Kamiya T, Saeki K, Nezu T, Takeuchi S, et al. (2010) Structural insights into the hot spot amino acid residues of mushroom tyrosinase for the bindings of thujaplicins. Bioorg Med Chem 18: 8112-8118.

20. Zhou B, Ikejima T, Watanabe T, Iwakoshi K, Idei Y, et al. (2009) The effect of 2-deoxy-d-glucose on Werner syndrome RecQ helicase gene. FEBS Lett 583: 1331-1336.

21. Uchiumi F, Watanabe T, Tanuma S (2010) Characterization of various promoter regions of human DNA helicase-encoding genes and identification of duplicated ets (GGAA) motifs as an essential transcription regulatory element. Exp Cell Res 316: 1523-1534.

22. Uchiumi F, Hatano T, Ito H, Yoshida T, Tanuma S (2003) Transcriptional suppression of the HIV promoter by natural compounds. Antiviral Res 58: 8998.

23. O'Sullivan RJ, Karlseder J (2010) Telomeres: protecting chromosomes agains genome instability. Nat Rev Mol Cell Biol 11: 171-181.

24. Blackburn E (2006) Chapter 1: A history of telomere biology. In: Telomeres ( $2^{\text {nd }}$ edn) (de Lang T, Lundblad V, Blackburn E, Eds.), Cold Spring Harbor Laboratory Press, NY: 1-19.
25. Vijg J (2007) Chapter 5: Genome instability and accelerated aging. In: Aging of the Genome: The Dual Role of DNA in Life and Death, Oxford University Press, NY: 151-180

26. Robb EL, Page MM, Stuart JA (2009) Mitochondria, cellular stress resistance, somatic cell depletion and lifespan. Curr Aging Sci 2: 12-27.

27. Benz CC, Yau C (2008) Ageing, oxidative stress and cancer: paradigms in parallax. Nat Rev Cancer 8: 875-879.

28. Cavallini G, Donati A, Gori Z, Bergamini E (2008) Towards an understanding of the anti-aging mechanism of caloric restriction. Curr Aging Sci 1: 4-9.

29. Kenyon CJ (2010) The genetics of ageing. Nature 464: 504-512.

30. Kaeberlein M (2010) Lessons on longevity from budding yeast. Nature 464 513-519.

31. Houtkooper RH, Pirinen E, Auwerx J (2012) Sirtuins as regulators of metabolism and healthspan. Nat Rev Mol Cell Biol 13: 225-238.

32. Uchiumi F, Higami Y, Tanuma S (2010) Chapter 5: Regulations of telomerase activity and WRN gene expression. In: Telomerase: Composition, Functions and Clinical Implications (Gagnon AN, Ed.), Nova Science Publishers, Inc Hauppauge, NY: 95-103.

33. Wierstra I (2008) Sp1: Emerging roles-Beyond constitutive activation of TATA less housekeeping genes. Biochem Biophys Res Commun 372: 1-13.

34. Okazaki M, Iwasaki Y, Nishiyama M, Taguchi T, Tsugita M, et al. (2010) PPAR $/ \delta$ regulates the human SIRT1 gene transcription via Sp1. Endocr J 57: 403-413.

35. Altarejos JY, Montminy M (2011) CREB and the CRTC co-activators: sensors for hormonal and metabolic signals. Nat Rev Mol Cell Biol 12: 141-151.

36. Lee MJ, Kim JW, Yang EG (2010) Hinokitiol activates hypoxia-inducible facto (HIF) pathway through inhibition of HIF hydroxylases. Biochem Biophys Res Commun 396: 370-375.

37. Lim JH, Lee YM, Chun YS, Chen J, Kim JE, et al. (2010) Sirtuin 1 modulates cellular responses to hypoxia by deacetylating hypoxia-inducible factor $1 \alpha$. Mol Cell 38: 864-878.

38. Liu S, Yamauchi H (2009) p27-Associated G1 arrest induced by hinokitiol in human malignant melanoma cells is mediated via down-regulation of $\mathrm{pRb}$ Skp2 ubiquitin ligase, and impairment of Cdk2 function. Cancer Lett 286: 240 249

39. Krenn BM, Gaudernak E, Holzer B, Lanke K, Van Kuppeveld FJM, et al. (2009) Antiviral activity of the zinc ionophores pyrithione and hinokitiol against picornavirus infections. J Virol 83: 58-64. 